\title{
Syntactic and Semantic Studies of the English Let-Constructions
}

\author{
WU Guoliang*, FENG Chuncan, WU Chun \\ Zhejiang Yuexiu University of Foreign Languages
}

*Corresponding Authors: WU Guoliang, Zhejiang Yuexiu University of Foreign Languages

\begin{abstract}
This article is to explore the syntactic and semantic features of the English Let-Constructions from a multidimentional view point of linguistics. The key topics include the potential meaning of let; the case of the pronoun after let; the argument of the passive forms of let; the meaning constraint of the speech act verb after let; the pragmatic functions of the discourse marker let us say, focusing on the syntactic form, semantic meaning and related pragmatic back ground of the construction.
\end{abstract}

Keywords: Syntactic, Semantic Studies, English Let-Constructions

\section{INTRODUCTION}

Letconstruction is a common structure in English, but its usage features are quite complicated. It has a long history of evolution, but there have been different views on it in the academic field. In traditional English, the analysis of the let construction is mostly based on the usage features. At present, the general dictionaries do not have an in-depth cognition of the syntax and semantics of the construction. And there is no rational comparison between allow and permit, which are commonly used as alternatives tolet. The characteristics of discourse markers such as let us say are rarely revealed. This paper intends to elaborate the structure from the perspective of linguistics and semantics in the following six aspects, in order to learn from the predecessors and peers.

\section{The Potential Meaning of LET}

For the basic meaning of let, many foreign dictionaries often use allow and permit to annotate. Oxford American Word power Dictionary (Urbom, 1998) paraphrases it as: let verb [T] 1. To allow or permit sb/sth to do sth; to allow sth to happen: My parents let me stay out until 11 o'clock. He wanted to have the day off, but his boss wouldn't let him. Wood (1981: 152) also uses allow and permit to paraphrase let.

From the perspective of synonyms, we hold that allow and permit can be used to paraphrase let, but it is better to add some necessary pragmatic labels, otherwise it seems that something is lost because of being too simple. In terms of stylistic style, there are definitely differences among the three words. let: to allow(informal); permit: to allow something officially (Bertram 1997: 11). In fact, the difference between them is much more than that. Their differences are mainly in the underlying semantic meanings.

Comparatively speaking, let lacks pragmatic strength besides being informal, while allow and permit contain the power and authority of prohibition and prevention. See the description of Gove (1984: 492) in Merriam-Webster's Dictionary of Synonyms: Let is the most informal ... sometimes let implies failure to prevent through awkwardness, inadvertence, negligence, or inaction (the third baseman let the ball get through him) ... and sometimes it implies failure to prevent through lack of power or inclination (he'll have to be a good deal tougher than his dad, who lets himself be pushed around Mead). Allow and permit imply power and authority to prohibit or prevent. But allow may imply little more than acquiescence or lack of prohibition, whereas permit implies express signification of willingness (the freedom of conscience allowed dissenters, the tolerance extended to all creeds Billington).

We hold that, generally speaking, one of the most obvious differences between let and allow and permit is whether there is an action or not. The inaction mentioned above is a distinguishing feature. Wierzbicka (2006: 188) has a related description: 
Unlike the case of the verb permit (X permitted $Y$ to do Z), the causer doesn't have to say anything; what matters is that the causer intentionally refrains from saying ' $N o$ ' and that because of this the causee can (and does) proceed.

See the following expansion of the letconstruction :(Wierzbicka (2006: 188)

Person $\mathrm{X}$ let person $\mathrm{Y}$ do $\mathrm{Z}$ (once). =

a. X knew that Y wanted to do Z

b. X knew that if $\mathrm{X}$ didn't say anything about this to $\mathrm{Y}, \mathrm{Y}$ would do it.

c. at the same time $\mathrm{X}$ knew that if $\mathrm{X}$ said to Y:"I don't want you to do this" Y could not do it.

d. X didn't say anything like this to Y.

e. because $\mathrm{X}$ didn't say anything like this to Y, Y could do Z.

f. $\mathrm{Y} \operatorname{did} \mathrm{Z}$

The explanation is that, from the speaker's point of view, $\mathrm{X}$ causes $\mathrm{Y}$ to do sth by abstinence from the interfering with behavior of $\mathrm{Y}$.

From this point of view, the meaning of let is really different from that of allow and permit at the deep level, there for the context used will be different, which is especially important for non-native English speakers.

The semantic history of English let-construction is a vast and fascinating topic, but the general trend is fairly clear: it is, on the whole, a shift from positive causation, in a very broad sense (often spanning, effectively, "action" and "inaction") toward "negative causation," that is, to"enabling by not preventing." (Wierzbicka 2006: 202).

Linguistic investigation shows that the potential meaning of let evolves over time. As Fischer (1992: 29) explains: let was "the central causative verb" in Middle English, and it had a distinct sense of "cause, allow", that is, a sense apparently spanning (like the German Lassen still does) "positive" and "negative" causation, but in fact interpretable in all cases in terms of "doing something." This is clearly not the case in contemporary English, in which let refers, by and large, to abstention from action rather than to action. It can be seen from this that in Middle English, there is a reason to annotate letwithallow because they have a common semantic basis and are therefore appropriate. But in contemporary English, let generally refers to avoiding action (abstention form action), rather than moving towards the action (to action).

Therefore, we hold that using allow and permit to annotate let, in dictionaries has a certain semantic basis, but it seems to be too simple for modern English, and it is better to add some pragmatic annotations.

\section{THE CASE OF THE Pronoun AfTer LET}

When let is used as aregular imperative verb, the case of pronouns following letshould not have been a problem. However, there are often inconsistencies between language practice and grammatical rules, which leads to different opinions in academic circles. In Usage and Abusage, Partridge (1999: 176) points out clearly: Let takes accusative, not the nominative; 'Let you and I go' is incorrect for 'Let you and me go'. Wood (1981: 152) has the same attitude: Let plus objective case. Let you and me always do our best (Not you and I). Let them (or those, but not they) who make wars fight them. Linguists repeatedly stress this, of course, because there are plenty of examples of language practice that contradict it. Fowler (1998: 453) has noticed this phenomenon: Mistakes in the choice of case can occur in English only in the personal pronouns, since only these have distinctive subjective and objective forms. However, he had to point out that: Such mistakes occur fairly often in unsophisticated speech in exhortation led by let: e.g. And now, my dear, let you and I say a few words about this unfortunate affair (read you and me). Although Fowler sees the problem, he believes it cannot be used as evidence to support the wrong structure of English today. It can be seen that his statement is somewhat of a linguistic purity.Evans (1957: 273) has a liberal description of the problem: When let is used as a regular imperative it cannot be followed by a subjective pronoun. That is, we say let John and me wash the dishes, and not Let John and I wash them. But at the same time, 
they pointed out the objective existence: But in actual practice, the subjective $I$, as in Let's you and I wash the dishes is preferred by many people including some of our best writers. The reasons given by Evans (1957) are: This could be defended, academically, on the grounds that let's is here merely a sign of the imperative, that the true imperative is wash, and you and $I$ its subject.

From the perspective of historical linguistics, the use of the nominative case after let has indeed a long history. Gilman (1994: 595) has a simple and clear description:

The OED has a $17^{\text {th }}$-century version of Malory with a "Let we ..."and our files included a modern instance from Trinidad:

“... a restaurant in Queen Street way we cud get good ahalpourri and chicken curry, let we go."

- Samuel Selvon, A Brighter Sun, 1952

Another phenomenon is that let followed by a pronoun which is again followed by an attributive clause, which is considered to be a more serious mistake by Fowler (1998: 453): A more serious error is to allow the subjective form of a pronoun to stand immediately after the exhortatory let: e.g. Let he who did this be severely punished (read him).

In terms of linguistic survey on the use of nominative case of pronouns after let, it is found that the pronoun is a compound phrase connected by and. Look at the example sentences given by Gilman (1994):

... let thee and I go on

—John Bunyan, Pilgrim's Progress, 1678(in Jespersen)

... let my dear and I talk the matter over

-George Farquhar, The Beaux Stratagem, 1707(in Jespersen)

The two components are often in apposition to $u s$, but remain the nominative case:

...let us make a covenant, I and thou

- Genesis 31:44 (AV), 1611The reason for the appearance of nominative pronouns in place of the objective in all these constructions, says Jespersen, is that the pronoun has come to be perceived as the subject of the following infinitive rather than the object of let. He calls it a notional or virtual subject. (Gilman 1994: 595). We hold that this phenomenon of let construction has been accepted by many people in Britain and America. The motivation for these phenomena is that the Principle of Proximity is at work. Because to is absent in front of the following infinitive, as a result, the second pronoun after and occurs directly before the verb. For the third example above, $I$ and thou is appositive for us, but they are directly related to predicate verbs. As for pronouns followed by attributive clauses, that is more influenced by attributive clauses led by who. The syntactic phenomenon that the relative pronoun who acts as the subject in the clause is also a temptation. On the other hand, these long-term tendencies in language practice have brought these uses closer to idioms. However, one thing is certain: the pragmatic context of these uses is informal or in oral English.

These, and also the absurd let's us (e.g. as let's us to go too), are many distant suburbs away from formal Standard English. In grammatical terms, let's in these constructions, is simply being treated as a quasi-modal pronounced / let's/, which is no longer perceived as a reduced form of $u s$ (Fowler 1998: 453). We hold that, in fact, this is also a concrete manifestation of the process of grammaticalization. Evans,B\&E vans, C. (1957:273) point out: Us is sometimes used after let's, as in let's us try it out. This construction is not often seen in print and is condemned by many grammarians as redundant, although it is hard to see why us is any more redundant than you and me. So Evans's attitude is open.

Until the 20th century, let's was frequently treated as a unit rather than as an abbreviation, and then it was followed by a pronoun. When the pronoun is us, the construction is criticized as superfluous, especially by earlier critics. Quirk et al. (1985) described let's us as familiar American English. (Gilman 1994: 595)

\section{Arguments Over the Passive Structure of Let}

There has been a debate in linguists about whether there exists a passive form of letconstruction. But the mainstream voice is that let has no passive structure. Fox (2013) clearly warned people in 
Longman Dictionary of Contemporary English that: Do not say 'be let to do something', because let has no passive from. Use the active form, or use be allowed. Collins COBUILD English Usage (1992: 354) also points out: There is no passive form of let. You do not say, for example, 'He was let go' or 'He was let to go'. If you want to use a passive form, you use a different verb, such as allow or permit.Perhaps when he grew up he would be allowed to do as he pleased. She was the only prisoner permitted to enter my cell. There is another opinion that is not so rigid. Swan (1987: 361)says: Let can't normally be used in passive sentences. Instead, we use allow (with a to-infinitive), or another word with the same meaning. Jan A. Van Ek and Nico J. Robat (1984332) think that the passive structure of let is very few: In the rare cases where let (=permission) occurs in the passive we find a complement in the form of a bare infinitive clause, a realization type found uniquely with this verb.

It oughtn't to have been let happen.

We also found hundreds of examples from the BNC corpus:

Nobody is let loose with these, sir. That is not how we manage things. Discipline is everything.

—Peyton, K.M., Who, Sir? Me, Sir?, 1988

I was wondering where I was going to be 'let free to do the work of the lord'

-Heald, Tim, A classic English crime, 1990

Wood (1973) holds the same view in English Verbal Idioms: the passive structure of let is not common, but we do stumble across this usage. For example: They were let look over the house. He also argued that it should usually be said: They were allowed to look over the house.

We hold that the reason why linguists and quite a few dictionaries emphasize repeatedly that let can not be used in passive voice, apart from hoping to express the standard uses of let, there does exist the fact that let is used by some people in British and American countries. The example of BNC is a kind of proof. And this usage has been around for a long time, and quite a few have come from the hands of famous experts:

Satan, aroused by the one shot, was snarling and panting to be let out.

—Jack London, Adventure, Chapter XI, 1911

You're not in a state to be let come upon strange parishes' ceptin as a casual.

\section{-Charles Dickens, Our Mutual Friend, Chapter 8, 1865}

The situation was sufficiently serious. The rocks could not be let go for a moment, and the blood was spurting out of more than twenty cuts. The most serious ones were in the head, and I vainly tried to close them with one hand, while holding on with the other.

-Mark Twain, A Tramp Abroad, Chapter xxxvi, 1910

We hold that these people using the passive form of let's, instead of changing let to allow, is in another way to confirm the deep semantic difference between let and allow.For the non-native speakers of English,however,do not use the passive structure of let.

\section{The Semantic Constraint of the Speech ACt Verb Following LET}

Traditional English researches on the let construction mostly focus on syntactic features and seldom mention the semantic requirements of the verb following let. Let's look at a set of comparative examples given by Wierzbicka (2006: 196):

Let me conclude by saying...

Let me explain/suggest/assure you...

*Let me order you... (Compare I order you ...)

? Let me beg you... (Compare I beg you ...)

The formula "Let me Verb" normally includes a verb of speech(Vsay)or a verb that can at least be interpreted as such, as a verb of sequence (e.g., Let me start with ...; let me now turn to...) 
Clearly, the most obvious semantic component of the "let me Vsay"construction is "I want to say something." However, the speaker also indirectly indicates his or her desire to involve the addressee in the speech act and to recognize the speaker (real or imaginary) as the existence and right of the participant in the communication process. (Wierzbicka 2006:196)

As can be seen from the last two sentences above, Let me order you ... and Let me beg you ..., Compared to I order you ... and I beg you, It is obviously restricted by the semantic meaning of the verb followinglet. The verb order, obviously does not meet the above semantic requirements, and, let me beg is a bit vague.

But according to Wierzbicka (2006: 197): Let me beg you would also sound odd, although I beg you is still quite acceptable, as is also let me suggest or let me explain. Here, the reason for this incongruity lies in the inequality between the speaker and the addressee, implied by the verb beg, and the implication of "equal rights" of the interlocutors, implied by the "let me Vsay" construction. (Compare also let me ask youv.s * let me order you).

We hold that Wierzbicka's" willingness to involve the addressee in speech acts" is insightful, but that is a little bit too absolute. Though the notion equal rights of the interlocutors is also an important factor, it exists only by comparison. The equal right has a problem of understanding, and objectively there is the possibility of a certain degree of self-deprecation. Linguistic investigations show that, let me order you does have problems, but let me beg you can exist under certain conditions. For the addressee, the speaker's slight condescension in language does not unduly affect the recipient's reaction, cooperation, and resonance. So beg and order are quite different. But from the logic of cultural linguistics, equal rights should be an important element of conversational harmony. In view of this, we have carried on the research in the BNC corpus, searching for the two structures let me order and the let me beg. No instances of let me order you... were found, while there are three examples for the structurelet me beg you .... :

BELVILLE: Equivocator again! What, do you talk of an argument? Is it holding an argument with me to answer a plain question? Answer me what I asked.

PAMELA: O, good sir, let me beg you will not urge me further for feat I forget myself again and be saucy.

—Morgan, Fidelis and Havergal, Giles, Pamela, 1987

But the use of Let me beg you in modern English in the 17th and 18th centuries is no exception. We have searched the English literature by computer and found 39 out of 50 million word frequency materials, many of them from the hands of celebrities:

Let me beg my young friend not to be found among this odious crowd of marplots.

—Anthony Trollope, Hunting Sketches, Chapter 7, 1865

Consider carefully, let me beg you, the case of a young man and a young woman who walk out of a door on Tuesday, pronounced man and wife by a third party inside the door.

-Owen Wister, The Virginian, A Horseman of the Plains - XXXIII. The Spinster Loses some sleep, 1902

"Do let me advise you not to mount her" hesaid, "she is a charming creature, but she is too nervous for a lady. I assure you, she is not perfectly safe; let me beg you to have the saddles changed."

—Anna Sewell, Black Beauty, Chapter 24, The Lady Anne, or a Runaway Horse, 1877

By analyzing the retrieval results of "let me _ vv0*" in Professor Mark Davies's COHA (Corpus of Historical American English), we found that, The V in let me $V s b$ structure, besides verbal verbs, can also be non-verbal verbs. No matter what kind of verb it is, "I" usually have no authority on the following object $\mathrm{sb}$ when doing this $\mathrm{V}$ action, and is not binding or mandatory on that object. The order, beg in discussion are a kind of verbal verbs of "demand", the former highlighting authority, constraint and compulsion, and the latter having no such meaning. In COHA, it is rare to use order inlet me ordersbwith the above mentioned meaning, but for verbs with no strong authority, constraint and compulsive meaning, apart frombeg, there is alsoentreat, which are, comparatively speaking, not very rare. However, verbs such as beg, entreat were used more frequently in the 19th century and less 
since the 20th century:

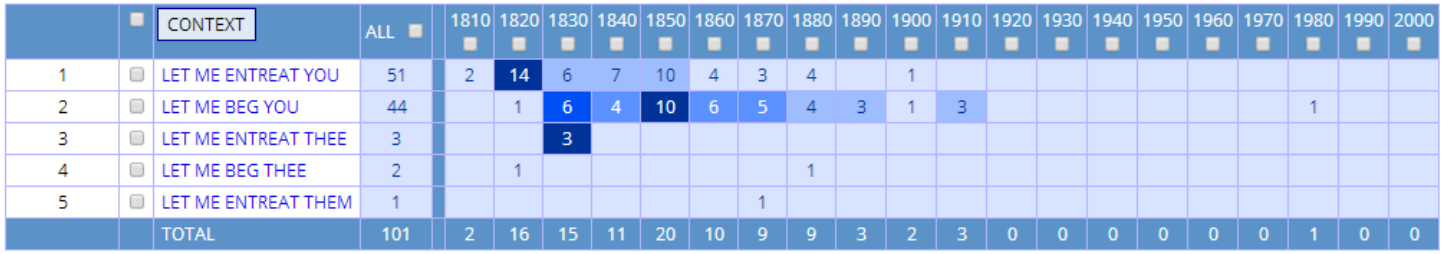

"It is true that I do not understand," he said, "but Dubravnik is my best friend and he will tell me all that is necessary to tell. In the meantime, I am commanded by his majesty, the czar, to remain at the palace for a few days. Letmeentreat you to regard everything here as your own."

—Beeckman, Ross, Princess Zara, 1909

Sir Spendall Flinty So deeply Louisa, that I should have gone to prison; for I do not know the friend -who would have bailed me, for so large a sum.

Louisa My dear father, letmeentreat you to confine yourself at home,' till you can be extricated; and again go abroad in safety.

-Pickney, Maria, The Orphans, 1818

When we address an artist or professional person of eminence, the style is different. My noble friend, I am in the greatest possible embarrassment, and you are the only person who can extricate me from it. Your assistance is indispensable to me. Letmebegyou to undertake the business, and make your own terms.

- The Art of Being Happy, North American Review, July 1828

Now, Mrs. Phillipetti, just letmebeg you not to say anything about it to anybody, and I'll have Detective Gubb get right on the case. The matter is in my hands. Rest easy! We will attend to it.

\section{-Butler, Ellis Parker, Philo Gubb, Correspondence-School Detective, 1918}

So it's clear that there are no examples for let me order, a structure with obvious semantic conflict, both in ancient and modern English. However, from the perspective of the use of let me beg you, there is still room for improvement in Wierzbicka's statement. Although the semantic meaning of beg itself is not in harmony with the pragmatic environment required by the let me Vsay structure, it is also an indisputable fact that quite a few examples existed before the 19th century. And many of them came from the hands of famous artists. However, language is developing in the process of change, and Wierzbicka's statement is reasonable for the contemporary English, but from the perspective of cultural linguistics, the "rights" of the interlocutors are indeed relatively speaking. This also gives the explanatory space for the three examples of let me beg youwhich occur occasionally. Of course, it is not suitable without doubt, for those whose English is not a native language to follow suit.

\section{Pragmatic Functions of Discourse Marker Let Us $S a Y$}

The common phrase let us say, which may seem simple, is actually not simple. Although most lexical books refer to it, they are often too brief and lacking in depth. In particular, its characteristics of discourse markers are lack of rational expression. Linguistic studies have shown that, the phraselet us say or let's say, let me say or even their simplified form say, is an information-centered expression marker with the function of expressing context and interaction. In the case of let us say, It is often used to express the relevance of the follow-on language to the previous context and to explain the speakers's attitude towards information and hearer. Therefore, it has the pragmatic characteristics of discourse markers. Its meaning varies from context to context and its form varies from style to style. This is especially noteworthy for the cognition and understanding of relevant languages, as well as for the translation between Chinese and English.

Oxford Word power Dictionary for Learners of English (Steel 2000) has an interpretation of let's say: Let's say for example: You could work two mornings a week, let's say Tuesday and Friday. Obviously, the explanation here accords with the characteristics of discourse markers. It's a pity that it's too simple to explain it completely. It is relatively much more informative in Cambridge Learner's Dictionary (Waiter 2001): (Let's) say used to introduce a suggestion or possible example of 
something.

Ball (1986: 96-97) listed Let us/me say and say as the same item in Dictionary of Link Words in English Discourse and described them as follows: These link words are suggestive. They offer an analogy; another form of words; a parallel idea (for purposes of comparison); or they put forward a proposal as a base for bargaining.

A song-writer

'I had to play auditions for professional backers and professional actors, and I also had to write professional songs. So I had a small catalogue - a portfolio, let us say, to demonstrate to producers around town.'

'Plomley’sPick' RoyPlomley (Weidenfeld \& Nicolson)

An offer

I'm willing to pay, say, $£ 100$ towards the project.

Linguist Swan (2005: 138-145) categorizes all entries involving making things clear; giving details; softening and correcting; giving examples into the discourse marker category. Therefore, let us say can be regarded as a discourse marker.

We hold that a thorough understanding of the syntactic and semantic relationships between let us say and others is beneficial to the learning and application of English language.

Syntactically, let can be followed by that clauses, which are often used as inserts and are fairly flexible.

Let's say that we'll need two hundred dollars to make the purchase.

-Halsey et al., Macmillan Dictionary, 1973

Let us apply it to two mutually perpendicular directions, the $\mathrm{X}$ and $\mathrm{Z}$ axes let us say.

Polkinghorne, J.C., The Quantum World, 1984

Let us say, $\mathrm{S}$ is the sentence covered by the whole tree, and $\mathrm{S}$ is the shorter sentence generated within it from B. S is a substring of S. Say L is the part of S to the left of S, and R is the part to the right.

-Hutchinson, Alan, Algorithmic Learning, 1991

In terms of semantics, many sentences differ from the literal meanings of let us say

Let's sayyour new spouse insists on his private space.

(=assume) (Herbst, et al. 2004)

Try and finish the work by, let's say, Friday.

(a suggestion or possible example)

Say/let's say (=If we accept) (that) the journey takes three hours you'll arrive at 20'clock. (Woodford 2005)

Therefore, to understand the features of the discourse marker let us say's can make us more rational and accurate in our cognition and translation of the relevant language materials.

\section{The MEANing OF LET THERE BE AND OTHER STRUCTURES}

Linguistic studies show that let often has different semantic and pragmatic functions with different lexical and structural collocations. They are by no means a simple superposition of the meaning of let and there bethemselves. Herbst et al. (2004) listed this sentence pattern in A Valency Dictionary of English: Let there be no misunderstanding on that score. Don't let there be war. Their pragmatic characteristics are also pointed out: If you say there be something you express your strong wish or hope that something should happen. Thomson \& Martinet (1986: 284) also explain the phrase let there be:

Here the speaker could be ordering, advising, urging or begging: 'Let there be no reprisals,' said the widow of the murdered man=The widow urged/begged that there should be no reprisals. 
It is recalled that in 2004, one of the then presidential candidates, John Forbes Kerry, ran for president with a serious claim that: Let there be no mistake: I will never hesitate to use force when it is required. (CNN: Kerry, We are here to make America stronger.)

Therefore, when we use this sentence pattern, we must pay attention to its pragmatic environment. For example, see the following sentence:

Let me catch these boys stealing my apples again, and I'll set the dog on them.(Wood 1973)

In fact, thefirst part of the sentence introduced bylet is formally an imperative clause, functionally equivalent to a conditional clause. Quirk et al (1985: 939) have a similar sentence: Let's put up the price and they'll cancer the order. The syntactic features of this kind of sentence are as follows: the first clause is in the form of imperative, the meaning is equivalent to the conditional clause, and is often used in the middle to connect two parts of the sentence. The latter clause often has a modal auxiliary verb. In fact, not only let imperative clause has this function, other forms of imperatives can also be used in this way.

The usage characteristics and pragmatic background of the negative form of let construction are not described here because of limited space. For this information, see Wu Guoliang (1991).

\section{CONCLUSION}

In this paper, the syntactic, semantic and pragmatic functions of let constructions are widely explored and discussed. This paper makes an in-depth study of differences between let and allow and permit from the perspective of linguistics. The paper reveals the real pragmatic conditions and pragmatic environment of let and the grammaticalization of let's, as well as the semantic constraints of the verb following let. Combined with the corpus-based investigation, this paper briefly expounds the pragmatic functions of the let constructions, interprets the passive form of let, and analyses the meaning and function of discourse markers let us say. The purpose of this paper is to strengthen the understanding of the deep problems of let construction and use the construction idiomatically.

Note: The asterisk (*) is the sign to indicate an ungrammatical structure.

\section{REFERENCES}

[1] Ball, W.J. Dictionary of Link Words in English Discourse [M]. London: Macmillan Publishers Ltd, 1986.

[2] Bertram, A. In Other Words [M]. Lincolnwood: NTC Publishing Group, 1997.

[3] Carney, F. LAROUSSE English Dictionary [M]. Paris: LAROUSSE/HER, 2000.

[4] Dalgish, G.M. Random House Webster's Dictionary of American English [M]. New York: Random House, Inc., 1997.

[5] Downing, A. \& Locke, P. A University Course in English Grammar [M]. London: Prentice Hall International (UK) Ltd, 2002.

[6] Van Ek, J.A. \& Robat, N.J. The Student's Grammar of English [M]. Oxford: Basil Blackwell Limited, 1984.

[7] Evans, B. \& Evans, C. A Dictionary of Contemporary American Usage [M]. New York: Random House, Inc, 1957.

[8] Fischer, O. Syntactic Change and Borrowing: The case of the accusative and infinitive construction in English [A]. In Marinel Gevitsen and Dieter Stein, eds. Internal and external factors in syntactic change [C]. Berlin: Mouton de Gruyter, 17-88, 1992.

[9] Fowler, H. (Revised third edition) \& Burchfield, R. Fowler's Modern English Usage, Oxford: Clarendon Press, 1998.

[10] Fox, C \& Combley, R. Longman Dictionary of Contemporary English, Longman: Pearson Education, 2013.

[11] Gilman, E.W. Merriam-Webster's Dictionary of English Usage [M]. Springfield: Merriam-Webster, 1994.

[12] Gove, P. Merriam-Webster's Dictionary of Synonyms [M]. Springfield: Merriam-Webster, 1996.

[13] Herbst, T., Heath, D., Roe, J.F., \& Gotz, D. A Valency Dictionary of English [M]. Berlin: Mouton de Gruyter, 2004.

[14] Quirk, R., Greenbaum, S., Leech, G., \& Svartvik, J. A Comprehensive Grammar of the English Language [M]. London: Longman Group Limited, 1985.

[15] Partridge, E. (New edition) \& Whitcut, J. Usage and Abusage [M]. London: Penguin Group, 1999. 
[16] Rundell, M. Longman Dictionary of English Language and Culture [M]. London: Addison Wesley Longman, 1998.

[17] Rundell, M. Macmillan English Dictionary for Advanced Learners [M]. London: Macmillan Publishers Limited, 2002.

[18] Sinclair, J. Collins COBUILD English Usage [M]. Glasgow: HarperCollins Publishers Ltd, 1992.

[19] Spears, R.A. (Second edition) Common American Phrases in Everyday Contorts [M]. New York: McGraw-Hill Education, 2003.

[20] Steel, M. Oxford Wordpower Dictionary [M]. Oxford: Oxford University Press, 2000.

[21] Swan, M. Practical English Usage [M]. Oxford: Oxford University Press, 1987.

[22] Swan, M. Practical English Usage (Third edition) [M]. Oxford: Oxford University Press, 2005.

[23] Thomson, A.J. \& Martinet, A.V. A Practical English Grammar (Fourth edition) [M]. Oxford: Oxford University Press, 1986.

[24] Urbom, R. Oxford American Wordpower Dictionary [M]. Oxford: Oxford University Press, 1998.

[25] Walter, E. Cambridge Learner's Dictionary [M]. Cambridge: Cambridge University Press, 2001.

[26] Wierzbicka, A. English Meaning and Culture [M]. Oxford: Oxford University Press, 2006.

[27] Wood, F.T. English Verbal Idioms [M]. London: Macmillan Press Ltd, 1973.

[28] Woodford, K. Cambridge Advanced Learner's Dictionary [M]. Cambrdige: Cambridge University Press, 2005.

[29] Wood, F.T. (Revised edition) \& Flavell, R.H. \& Flavell, L.M. Current English Usage [M]. London: Macmillan Press Limited, 1981.

[30] WU Guoliang. On the Use and Characteristics of Imperative Sentences [J]. Journal of Foreign Languages. 1991(2).

\section{AUTHORS' BIOGRAPHY}

Dr. WU Guoliang, PhD, Professor of Zhejiang Yuexiu University of Foreign Languages, PhD Supervisor of Zhejiang University, Distinguished Visiting Professor of Arkansas State University, USA. His main interest includes Linguistics, Pragmatics, and translation. Address to No.428 Kuaiji Road, Yuecheng District, Shaoxing, Zhejiang, 312000, China.

FENG Chuncan, Associate Professor of Zhejiang Yuexiu University of Foreign Languages. His main interest includes linguistics, Pragmatics and Corpus linguistics.

WU Chun, Lecturer of Zhejiang Yuexiu University of Foreign Languages. Her main interest includes Semantics and Applied linguistics.

Citation: WU Guoliang, et.al. "Syntactic and Semantic Studies of the English Let-Constructions" International Journal on Studies in English Language and Literature (IJSELL), vol 8, no. 6, 2020, pp. 12-20. doi: http://dx.doi.org/10.20431/2347-3134.0806002.

Copyright: (c) 2020 Authors. This is an open-access article distributed under the terms of the Creative Commons Attribution License, which permits unrestricted use, distribution, and reproduction in any medium, provided the original author and source are credited. 